\title{
Does sharing the cost of a bicycle helmet help promote helmet use?
}

\author{
Allegra N Kim, Frederick P Rivara, Thomas D Koepsell
}

\begin{abstract}
Objective-To determine whether asking for a $\$ 5.00$ donation for bicycle helmets, compared with distribution free of charge, would affect helmet use among children receiving helmets and an educational intervention from public health clinics.
\end{abstract}

Setting-Six public health clinic sites in King County, Washington.

Methods-Six participating clinic sites were randomly assigned to either free helmet distribution or to a $\$ 5.00$ suggested donation for the helmets, stratified by whether a helmet law was in place. Three sites were assigned to each arm. Children who were between 6 and 12 years of age and who reported riding bicycles, but having no bicycle helmets, were eligible. Clinicians distributed helmets and delivered an educational intervention to 506 eligible children, or siblings of children seen at the clinic between March and July 1993. Parents were contacted after helmet distribution to ascertain helmet use.

Results-82\% of children whose parents were asked for a copayment and $77 \%$ of children who received free helmets were reported to wear their helmets every time they rode their bicycles $(p=0.20)$. The adjusted odds ratio for the association between copayment compared with free helmets and helmet use was 1.66 (95\% confidence interval 0.94 to 2.92 ).

Harborview Injury Prevention and Research Center and Department of Epidemiology, University of Washington School of Public

Health and

Community Medicine,

Seattle, USA

AN Kim

FP Rivara

Harborview Injury

Prevention and

Research Center and

Departments of

Epidemiology and

Health Services,

University of

Washington School of

Public Health and

Community Medicine,

Seattle, USA

TD Koepsell

Correspondence to:

Professor FP Rivara

Harborview Injury

Prevention and Research

Center, Box 359960, 325

Ninth Avenue, Seattle, WA

98104-2499, USA.
Conclusions-Helmet use was not significantly different among children whose parents were asked for a small copayment, compared with those who received helmets free. Use of copayments can increase helmet use by increasing the number of helmets given to low income children.

(Injury Prevention 1997; 3: 38-42)

Keywords: bicycle helmets; copayment; intervention

Bicycle related injuries are a major cause of death and disability in children under 18 years of age. In the US, traffic related bicycle mishaps accounted for approximately 580000 emergency department visits, 23000 hospital admissions, and over 800 deaths every year between 1987 and $1991 .^{1}$ Head injury is the most common cause of bicycle related deaths and serious disabilities. ${ }^{2}$ One third of bicycle crash victims treated in emergency rooms have head injuries, as do two thirds of those admitted to hospitals. ${ }^{2}$ A Seattle area study reported that $68 \%$ of head injuries occurred in bicyclists who were less than 15 years old. ${ }^{2}$ Th $\widehat{\widehat{D}}$ same study showed that most head injuries are preventable: bicyclists who wore helmets were $85 \%$ less likely to suffer head injuries and $88 \%$ less likely to sustain brain injuries than were those who did not wear helmets. ${ }^{2}$

Although earlier studies showed that bicycle helmet use was quite low, it has recently increased in many communities as a result of promotion efforts and legislation. Reaching lower income populations presents a particular challenge, with the cost of helmets being an important barrier to their use. This problenఖ has been addressed by offering subsidies coupons, less costly helmets, and free helmets $\overrightarrow{c o}$ In 1993, the Seattle-King County Departmene of Public Health obtained funds to distribute helmets to children through their public healti clinics. We postulated that requesting copay ments as an alternative to giving helmets awaw might cause recipients to place greater value oro their helmets, and thereby increase their use Also, collecting even a small payment wouls partially offset the cost and/or enable the Seattle-King County Department of Publif Health to buy more helmets. The purpose of this study was to determine whether requestin a $\$ 5.00$ copayment for a helmet, compare with providing helmets free of charge, woul affect their rate of use.

\section{Methods}

This study was approved by the Institutionati Review Board of the University of Washington $\frac{\mathrm{O}}{3}$

\section{HELMET DISTRIBUTION}

Six Seattle-King County Department of Publie Health clinic sites participated in the studyo Shortly before the study was launched, Kingu County enacted legislation requiring bicyclist under the age of 18 years to wear helmets, but the law was not in effect in the City of Seattle To avoid confounding the effect of this lave with the effect of copayment, one Seattle clinice and two non-Seattle clinics were assigned ato random to each of the two study arms. Clinice in one arm distributed helmets free, while those in the other arm requested a $\$ 5.0 \notin$ copayment. Clinic employees asked parents guardians accompanying children to clinic for immunizations, minor illness, well child care? or dental care, to complete a brief baseline questionnaire to determine whether any of their 6 to 12 year old children rode bicycles, and if so, whether they had a bicycle helmet. Public health nurses who made home visists to families with young children also asked that parents complete the questionnaires. Providers 
(doctors or nurses) then assessed eligibility and need for helmets by 6 to 12 year old children who rode bicycles but did not have a helmet. Providers also offered helmets to eligible siblings, even if they were not present. Providers either informed the recipients that the helmets were free, or requested $\$ 5.00$, depending on the clinic's assignment. If a parent was unable to pay the $\$ 5.00$ the clinics accepted $\$ 3.00$, or gave the helmet free.

\section{EDUCATION COMPONENT}

We asked providers at all sites to deliver the same message about the importance of helmet use for every ride and the correct way to wear a helmet. Providers' instructions were to fit the helmets to the children whenever possible and to explain that the helmet should be worn over the forehead, with the chin strap snug and fastened. We gave providers written suggestions for the verbal educational message. Briefly, these suggestions included:

- Explain the importance of wearing the helmet every time the child rides a bicycle.

- Tell the parents that they should also wear helmets for protection and as role models.

- Tell the child briefly what a brain injury is.

- Point out that sports figures wear helmets.

- Emphasize that wearing a bicycle helmet would decrease the risk of severe injury.

We gave providers materials to distribute with the helmets, including activity books and brochures for families. We also gave the doctors and nurses 'Wear a bike helmet' buttons and bicycle safety posters for the waiting and examination rooms.

\section{DATA COLLECTION}

In addition to eligibility information, providers recorded children's and parents' names, addresses, and telephone numbers during the clinic visit. They asked parents to sign consent forms, which explained that the study's purpose was to determine the best way to get helmets to kids. Two to three weeks after a child received a helmet, we sent a packet with a hand signed letter, a brief follow up questionnaire for each helmet distributed to that family, and a self addressed, postage paid envelope. The letter thanked the parent for participating and requested completion and return of the questionnaire. We collected information about the child's bicycling and helmet use since receiving the helmet; sex, birth date, residence zip code; and parent's education level.

We made up to three attempts to reach respondents by mail, and several attempts by telephone. A few respondents received no mailings, and were contacted by telephone only. The questionnaire administered by telephone was identical to that mailed, and the method of successful contact (mail or telephone) was recorded. The same trained interviewer conducted all telephone interviews in the same manner. When a parent felt unable to answer the questions because the child had not had sufficient opportunities to ride, the interviewer contacted the parent later.

\section{DATA ANALYSIS}

Responses to the question, 'How often does your child wear the bicycle helmet?' were grouped into two categories by combining 'Never', 'Less than half the time', 'About half the time', and 'More than half of the time'. 'Every time' was the other category and was termed 'consistent helmet use'.

To account for the non-independence of observations on individual children, we used generalized estimating equations (GEE) to analyze the data. The GEE methodology accounts for potential correlation among multiple helmet recipients, generally siblings, from the same family. ${ }^{34}$ Logistic regression under GEE yields adjusted odds ratios to measure the associations between consistent helmet use and copayment.

\section{Results}

There were 506 children who received helmets and whose parents were sent the questionnaire: 288 in the free helmet group, and 218 in the copay group. We obtained outcome information from $243(84.4 \%)$ of the former, and 180 $(82.6 \%)$ of the latter.

Table 1 shows the characteristics of the subjects by free versus copay category. A majority of the 'free' group were boys, whereas the opposite was true for the 'copay' group $(p=0.01)$. While the children's ages were similar $(p=0.44)$, the children in the two groups differed in several other ways. Parents in the copay group tended to be better educated $(p=0.01)$. Furthermore, most of the subjects in the free group lived in areas where the median income was in the first and last quartiles, whereas most of the subjects in the copay group lived in areas where the median income was in the second and third quartiles for the study population $(p<0.01)$.

Table 1 also shows that fewer recipients in the free group responded to mailed questionnaires $(p=0.02)$. A greater proportion of the free group $(62.6 \% v 52.2 \%)$ lived outside the

Table 1 Selected study variables by helmet distribution method; values are \% except for age

\begin{tabular}{|c|c|c|c|}
\hline Variable & $\begin{array}{l}\text { Free } \\
(n=243)\end{array}$ & $\begin{array}{l}\text { Copay } \\
(n=180)\end{array}$ & $p$ Value \\
\hline Girl & 42.6 & 55.7 & 0.01 \\
\hline $\begin{array}{l}\text { Mean (SD) child's age } \\
\text { (years) }\end{array}$ & $9.3(2.0)$ & $9.1(2.0)$ & 0.44 \\
\hline $\begin{array}{l}\text { Parent's equaction level } \\
\text { Less than high school } \\
\text { High school or more }\end{array}$ & $\begin{array}{l}29.8 \\
70.2\end{array}$ & $\begin{array}{l}18.5 \\
81.5\end{array}$ & 0.01 \\
\hline $\begin{array}{l}\text { Median income of zip code } \\
\text { Less than } \$ 30834 \\
\$ 30834-\$ 34019 \\
\$ 34020-\$ 40013 \\
\$ 40014-\$ 61223\end{array}$ & $\begin{array}{l}35.8 \\
17.3 \\
17.3 \\
29.6\end{array}$ & $\begin{array}{l}14.4 \\
32.2 \\
43.3 \\
10.0\end{array}$ & $<0.01$ \\
\hline $\begin{array}{l}\text { Method of follow up } \\
\text { Mailed questionnaire } \\
\text { Telephone interview } \\
\text { Helmet law in effect? }\end{array}$ & $\begin{array}{l}69.6 \\
30.4\end{array}$ & $\begin{array}{l}80.0 \\
20.0\end{array}$ & 0.02 \\
\hline $\begin{array}{l}\text { Yes } \\
\text { No }\end{array}$ & $\begin{array}{l}62.6 \\
37.4\end{array}$ & $\begin{array}{l}52.2 \\
47.8\end{array}$ & 0.03 \\
\hline $\begin{array}{l}\text { Wore helmet on last ride? } \\
\text { Yes } \\
\text { No }\end{array}$ & $\begin{array}{l}88.2 \\
11.8\end{array}$ & $\begin{array}{l}6.1 \\
93.9\end{array}$ & 0.05 \\
\hline
\end{tabular}


City of Seattle and were, therefore, subject to the helmet law $(p=0.03)$. Altogether $88.2 \%$ of children in the free group were reported to have worn their helmets on their last bicycle ride compared with $93.9 \%$ in the copay group $(\mathrm{p}=0.05)$

Table 2 shows how consistent helmet use varied in relation to characteristics of the study population. Helmet use was similar for the two distribution methods: $76.5 \%$ of the free group reported consistent helmet use compared with $81.7 \%$ of the copay group $(p=0.20)$. Girls were more likely to wear their helmets on every bicycle ride than were boys $(p=0.02)$. Children under age 10 were more consistent helmet users, with $81.9 \%$ reportedly wearing their helmets consistently, compared with $74.6 \%$ of children age 10 and older $(p=0.07)$. Although helmet use varied slightly by median income of the subjects' residence zip code, the difference was not statistically significant $(p=0.27)$. Nor was use associated with whether a helmet law was in effect $(p=0.87)$. Helmet use did differ by method of follow up: $81.5 \%$ of subjects whose responses were mailed in reported consistent helmet use compared with only $70.9 \%$ interviewed by telephone $(\mathrm{p}=0.02)$.

Table 3 shows odds ratios for the association between copayment and helmet use, with adjustment for potential confounders. The crude odds ratio for copayment and helmet use is 1.36 (95\% confidence interval (CI) to 0.77 to 2.41 ).

Using the 1990 US Bureau of Census Report STF3B File, we determined median household incomes for each zip code area and grouped the figures by quartiles. The resulting variable, 'median income of zip code', was considered a possible confounder of the association between copayment and helmet use. After adjustment for this variable, the odds ratio for the association was 1.66 (95\% CI 0.94 to 2.92 ). However, the CI for this odds ratio was quite wide and thus does not rule out a modest effect that might be statistically significant in a larger study. Other covariates, including age, sex,

Table 2 Characteristics of the study population by helmet use

\begin{tabular}{|c|c|c|c|}
\hline Characteristics & No & $\begin{array}{l}\text { \% Consistent } \\
\text { helmet users }\end{array}$ & p Value* \\
\hline \multicolumn{4}{|l|}{ Distribution method } \\
\hline Free & 243 & 76.5 & \\
\hline Copay & 180 & 81.7 & 0.20 \\
\hline \multicolumn{4}{|l|}{ Child's sex } \\
\hline Girl & 199 & 83.9 & \\
\hline Boy & 214 & 74.3 & 0.20 \\
\hline \multicolumn{4}{|l|}{ Child's age (years) } \\
\hline$\leqslant 9$ & 238 & 81.9 & \\
\hline$\geqslant 10$ & 185 & 74.6 & 0.07 \\
\hline \multicolumn{4}{|l|}{ Parent's education level } \\
\hline Less than high school & 104 & 76.9 & \\
\hline High school or more & 312 & 79.5 & 0.58 \\
\hline \multicolumn{4}{|l|}{ Median income of zip code } \\
\hline Less than $\$ 30834$ & 113 & 77.9 & \\
\hline$\$ 30834-\$ 34019$ & 100 & 74.0 & \\
\hline$\$ 34020-\$ 40013$ & 120 & 78.3 & \\
\hline$\$ 40014-\$ 61223$ & 90 & 85.6 & 0.27 \\
\hline \multicolumn{4}{|l|}{ Helmet law in effect? } \\
\hline Yes & 246 & 78.5 & \\
\hline No & 177 & 79.1 & 0.87 \\
\hline \multicolumn{4}{|l|}{ Method of follow up } \\
\hline Mailed questionnaire & 313 & 81.5 & \\
\hline Telephone interview & 110 & 70.9 & 0.02 \\
\hline
\end{tabular}

Table 3 Odds ratios for copayment and consistent helmet use

\begin{tabular}{lll}
\hline Adjustment variable & $\begin{array}{l}\text { Adjusted odds } \\
\text { ratio for copay }\end{array}$ & $95 \%$ CI \\
\hline Reference (unadjusted) & 1.36 & $(0.77$ to 2.41$)$ \\
Child's age & 1.33 & $(0.75$ to 2.15$)$ \\
Child's sex & 1.27 & $(0.79$ to 2.24$)$ \\
Median income of zip code & 1.66 & $(0.94$ to 2.92$)$ \\
Parent's education level & 1.34 & $(0.79$ to 2.29$)$ \\
Telephone interview & 1.29 & $(0.76$ to 2.17$)$ \\
\hline
\end{tabular}

parent's education level, and method of follow up did not confound the association betweerom copayment and helmet use.

\section{Discussion}

Prior studies show that bicycle helmet use is relatively difficult to increase in low income populations through the usual avenues oథ media and community events. ${ }^{56}$ The high cost of safety helmets is believed to be a major deterrent to helmet ownership, particularly ina low income populations. ${ }^{78}$ Economic subsidies in the form of discount coupons, rebates, or lower prices through bulk buys or agreementso with manufacturers have been used to promote helmet use in low income children, usuall accompanied by an educational components Success in increasing helmet use often require at least two components-education and leg? islation, ${ }^{9-11}$ or education and cost reduction. ${ }^{10}$ In their infant car seat study, Robitaille an $\vec{\Phi}$ colleagues concluded that it is not enough to provide low income parents with safety equip ment; parents must also be instructed in proper. and consistent use. ${ }^{13}$

Our helmet promotion effort appeared to be successful in achieving consistent helmet use compared with other helmet promotion efforts Several important distinctions between ou?

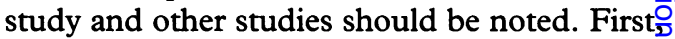
this study followed up only those children who did not own helmets at baseline but received. them through the study. Community base $\$$ promotion campaigns typically follow up po pulations in which many individuals may have had no exposure to the campaign. Follow us for the present study, however, included only: those whose parents had some contact with provider to obtain helmets through our study It is, therefore, not surprising that while othen studies have observed helmet use rates welly below $40 \%^{12}{ }^{14-17}$ ours found a high prevalence of reported consistent use.

Second, the interventions in the presents study consisted of providing both helmets and education to individuals. Clinicians had contact with individual parents and children as Schneider et al recommend to increase the effectiveness of helmet promotion. ${ }^{18}$ Cushmano and colleagues, however, report that physician counseling, in conjunction with take home pamphlets but no helmets or helmet coupons had no positive effect on use. ${ }^{19}$ Unlike the Cushman study, ours provided helmets in conjunction with the counseling and take home information.

Finally, the community in which the present study was conducted is unusual in that it has, 
partly as a result of a major helmet promotion campaign conducted since 1987 , a high rate of use in the population at large. ${ }^{12} 20 \mathrm{With}$ most of the stigma of helmet use removed by their rising popularity, ${ }^{7}$ one of the main barriers to children's use of helmets had already been overcome before we started the study.

\section{COPAYMENT}

We thought requesting copayment might have the advantages of increasing the perceived value of the helmets and therefore the likelihood of their use, as well as offsetting the cost to the Seattle-King County Department of Public Health, thus permitting greater distribution. These advantages raise the concern that the poorest families would not get a helmet because of inability to pay even a small copayment. In this study, however, the copayment was not strictly required: it was decreased to $\$ 3$ in some cases, or given free when necessary. Because no eligible children were refused helmets, this method of requesting, but not requiring, copayment should result in as wide a distribution of helmets as would giving them away.

\section{LIMITATIONS}

This study has a number of potential limitations. Whether the copayment was actually made at 'copay' sites is unknown for some of the subjects. Some clinicians at copay sites did not diligently pursue copayments, and some clients could not afford the copayments, particularly if they needed several helmets. The 'copay' group, therefore, includes some 'crossover' subjects who received helmets free, despite having gone to copay sites. This would result in an underestimate of the effect of copayment. It is possible that there is a true, positive effect of copayment, but that we were unable to observe it because of the contamination of the 'copay' treatment group. The intervention was realistic in that representatives of the clinics opposed a strictly required copayment.

Another potential limitation is that parents' reports of children's helmet use may be inaccurate, partly because parents cannot observe their children's behavior at every instant, and partly because there may be a social desirability bias to report high compliance. Direct observation of children was not possible with our resources. However some researchers believe that low income respondents may be less concerned with social desirability, and therefore less inclined to exaggerate. ${ }^{12}$ Furthermore, we suspect that parents in one arm of the experiment are no more likely to misreport than parents in the other arm. Therefore, even if parents exaggerate helmet use, the effect is unlikely to change the observed relationship between copayment and helmet use.

Because all follow up contacts were made within four months of receipt of the helmets, we can draw no conclusions regarding helmet wearing behavior over longer periods of time. We have no reason to believe that long term behavior would change more for one group than the other, however.

We were surprised to find that reported helmet use was lower among the telephone interviewed respondents. This difference might be explained by the fact that the telephone was the last resort for following up some respondents. Respondents who did not return completed questionnaires may be less likely to comply with advice from their health care providers. However, adjusting for the method of follow up had essentially no effect on the odds ratio for copayment and helmet use.

Our inability to randomize individuals rather than clinics poses another limitation. A randomized controlled trial of families or individuals would have been the preferred method to achieve greater similarity between treatment groups. Such a trial could not be implemented in the public health clinic setting due to the demands it would have placed on providers.

The method of randomization used also posed challenges for the proper analysis of the data. We used the GEE to accommodate the non-independence of data on different children within the same household. However, available software was not able to account additionally for the non-independence among families whose children received care from the same clinics, which were the units of randomization. We tried to address this problem in part by including child and family characteristics that might differ among clinics as covariates. However, the usual effect of analyzing group randomized data at the individual person level is to exaggerate the statistical significance of a treatment effect. Because we found no statistically significant copayment effect, this shortcoming is unlikely to affect the study's conclusions.

\section{Conclusion}

Copayment in conjunction with education was not statistically significantly associated with more consistent helmet use than free distribution in conjunction with education. Both free and copayment programs appear to be highly effective in achieving consistent helmet use by low income children in a public health clinic population. Because use of copayment can increase the number of helmets distributed, it is likely to increase helmet use in the target population as a whole.

The authors gratefully acknowledge the clinicians with the Seattle-King County Department of Public Health, who conducted the interventions. Many thanks also to Lisa W Rogers, Soyeon Kim, PhD, and Bob Soderberg.

Funding for this study was provided by Grant No RYG/ Funding for this study was provided by Grant No RYG/
CCR002570 from the Centers for Disease Control and Prevention, and the Seattle-King County Department of Public Health.

1 Baker SP, Li G, Fowler C, Dannenberg AL. Injuries to bicyclists: a national perspective. St James, NY: Johns Hopkins University Injury Prevention Center and the Snell Memorial Foundation, 1993.

2 Thompson RS, Rivara FP, Thompson DC. A case-contro study of the effectiveness of bicycle safety helmets. $N$ Engl f Med 1989; 320: $1361-7$.

3 Zeger SL, Liang K-Y. Longitudinal data analysis for discrete and continuous outcomes. Biometrics 1986; 42:

4 Liang K-Y, Zeger SL. Longitudinal data analysis using generalized linear models. Biometrika 1986; 73: 13-22. 
5 Parkin PE. Spence LJ, Hu X, Kranz KE, Shortt LG, Wesson DE. Evaluation of a promotional strategy to increase bicycle helmet use by children. Pediatrics 1993; 91: $772-7$.

6 Centers for Disease Control. Bicycle helmet promotion programs-Canada, Australia, and United States. MMWR 1993; 42: 203-9.

7 DiGuiseppi CG, Rivara FP, Koepsell TD. Attitudes toward bicycle helmet ownership and use by school-age children. Am 7 Dis Child 1990; 144: 83-6.

8 Wood T, Milne P. Head injuries to pedal cyclists and the promotion of helmet use in Victoria, Australia. Accid Anal Prev 1988; 20: $177-85$.

9 Cote TR, Sacks J, Lambert-Huber DA, et al. Bicycle helmet use among Maryland children: effect of legislation and education. Pediatrics 1992; 89: 1216-20.

10 Dannenberg AL, Gielen AC, Beilenson PL, Wilson $\mathrm{MH}_{\text {, }}$ Joffe A. Bicycle helmet laws and educational campaigns: an evaluation of strategies to increase children's helmet use. Am ₹ Public Health 1993; 83: 667-74.

11 Vulcan AP, Cameron MW, Heiman L. Evaluation of mandatory bicycle helmet use in Victoria, Australia. 36th Annual Proceedings of the Association of Automotive 36th Annual Proceedings of the Association of Auton 12 Bergman AB, Rivara FP, Richards DD, Rogers LW. The Seattle children's bicycle
Child 1990; 144: 727-31.
13 Robitaille Y, Legault J, Abbey H, Pless IB. Evaluation of an infant car seat program in a low-income community. $A m$ 7 Dis Child 1990; 144: 74-8.

14 Weiss BD. Trends in bicycle helmet use by children: 1985 to 1990. Pediatrics 1992; 89: 78-80.

15 DiGuiseppi CG, Rivara FP, Koepsell TD, Polissar L $\overline{-}$ Bicycle helmet use by children. $¥ A M A$ 1989; 262: 2256 . 61 .

16 Morris BAP, Trimble NE. Promotion of bicycle helmet use among schoolchildren: a randomized clinical trial. Can $\vec{f}$. Public Health 1991; 82: 92-4.

17 Pendergrast RA, Ashworth CS, DuRant RH, Litaker M Correlates of children's bicycle helmet use and short-terry failure of school-level interventions. Pediatrics 1992; 90 354-8.

18 Schneider ML, Ituarte $P$, Stokols $D$. Evaluation of community bicycle helmet promotion campaign: what works and why. American fournal of Health Promotion 1993; 7: $281-7$.

19 Cushman R, James W, Waclawik H. Physicians promotin

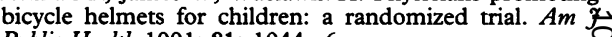
Public Health 1991; 81: 1044-6.

20 Rivara FP. Thompson DC Thompson RS, et al. The Seattle children's bicycle helmet campaign: changes in helmet use and head injury admissions. Pediatrics 1994. 93: $567-9$.

\section{Road rage}

A taxi driver in the UK was recently found guilty of causing the death of a cyclist in a road rage row. The driver 'swerved violently and deliberately' at the cyclist and then sped off without stopping, leaving his victim with fatal head injuries. The driver had earlier been delayed in a traffic jam caused by an anticar demonstration of cyclists. Apparently the pair had argued at a red light a while before the incident occurred. 'As they approached a zebra crossing later the taxi suddenly, violently, and deliberately swerved, causing the cyclist to lose control'. The driver told the jury that the victim was 'like a lunatic' and blamed him for 'cutting me up' and then acting like a madman in the ensuing argument (Guardian, 1996).

\section{Odd spot}

Depressed Roy Dolan turned on the gas in a suicide bid, but lit a cigarette when he had second thoughts. The blast wrecked a four home block of flats (Age, 15 July 1996).

\section{Brahms concert turns into rhapsody in red}

This delightful item from the Cape Argus paper, 24 September 1996, tells the tale of what happened when the New Zealand Symphony Orchestra and the Orpheus choir had begun performing Brahms' Alto Rhapsodie. The conductor dislocated his shoulder and a substitute entered, but without his glasses, causing him somehow to cut his thumb and bleed all over the music. Worse still, lacking glasses he could not read the score and conduct properly.

\section{Medieval defence}

A man in Sidbury, England facing a drink driving charge has asked his lawyers to examine if he has any defence under a medieval charter that established the Sidbury Fair. His question is whether the charter, established in the 14th century, removed the powers of arrest from police during the fair. The problem is finding a copy of the charter. Poor man! (G Gibbs, Guardian). 